\title{
Combating oncogene activation associated with retrovirus-mediated gene therapy of X-linked severe combined immunodeficiency
}

B.E. Strauss ${ }^{1,3}$ and E. Costanzi-Strauss ${ }^{2,3}$

\section{Correspondence \\ B.E. Strauss \\ Instituto do Coração, FM, USP \\ Av. Dr. Enéas C. Aguiar, 44 \\ Bloco 2, $10^{\circ}$ andar \\ 05403-000 São Paulo, SP \\ Brasil \\ Fax: +55-11-3069-5022 \\ E-mail: bstrauss@usp.br \\ Research supported by FAPESP \\ (Nos. 00/12156-5 and 98/15120-0) \\ and CNPq (Nos. 473587/04-1 and \\ 420036/2005-9).}

Received June 28, 2006

Accepted December 13, 2006

\author{
1Setor de Vetores Virais, Laboratório de Genética e Cardiologia Molecular, \\ Faculdade de Medicina \\ ${ }^{2}$ Departamento de Biologia Celular e do Desenvolvimento, Instituto de Ciências \\ Biomédicas, Universidade de São Paulo, São Paulo, SP, Brasil \\ ${ }^{3}$ Instituto do Milênio: Rede de Terapia Gênica, MCT, Brasília, DF, Brasil
}

\begin{abstract}
A successful gene therapy clinical trial that also encountered serious adverse effects has sparked extensive study and debate about the future directions for retrovirus-mediated interventions. Treatment of $\mathrm{X}$-linked severe combined immunodeficiency with an oncoretrovirus harboring a normal copy of the $\gamma c$ gene was applied in two clinical trials, essentially curing 13 of 16 infants, restoring a normal immune system without the need for additional immune-related therapies. Approximately 3 years after their gene therapy, tragically, 3 of these children, all from the same trial, developed leukemia as a result of this experimental treatment. The current understanding of the mechanism behind this leukemogenesis involves three critical and cooperating factors, i.e., viral integration, oncogene activation, and the function of the therapeutic gene. In this review, we will explore the causes of this unwanted event and some of the possibilities for reducing the risk of its reoccurrence.
\end{abstract}

\section{Introduction}

The clinical history of gene therapy is quite short, dating back only to 1990 . The first gene therapy trial was the retrovirusmediated gene transfer of a normal copy of the adenosine deaminase (ADA) gene for the treatment of immune deficiency caused by the loss of cellular ADA. This trial and others for ADA-X-linked severe combined immunodeficiency (ADA-X-SCID) have provided clinical benefit without side effects associated with the retroviral vector (1).
Key words

- Retrovirus

- Insertional mutagenesis

- Severe combined

immune deficiency

- Gene therapy

- Adverse event

- Clinical trial
A critical point in developing any gene therapy strategy is matching the vector to its application. Viral vectors are widely used since they rely on naturally occurring mechanisms in order to deliver genetic material to a target cell (Table 1). Adenovirus, for example, is well suited for applications that do not require long-term expression. Adeno-associated virus may safely provide sustained expression, but the applicability of this vector to the hematopoietic system is controversial (2). Currently, much study is focused on the safety of lentiviral vectors since their integration in the host ge- 
nome seems to be less likely to cause an adverse effect, though clinical experience with these vectors is limited. In contrast, retroviral vectors have a long history in the laboratory and in the clinic, their popularity being due to their ease of use and stability in the transduced cell.

Although much has been learned about the choices of gene transfer vectors, disease targets and therapeutic genes, the relatively limited success and highly publicized risks indicate a clear need for further improvement before gene therapy will become widely accepted. The risk and benefits of gene therapy are typified by the clinical trial for XSCID conducted by Drs. Alain Fischer and Marina Cavazzana-Calvo and colleagues (Hôpital Necker Enfants Malade, Paris, France). In that trial, a normal copy of a defective gene was introduced via retroviral transduction into hematopoietic stem cells of 1- to 11-month-old infants. The trial was extremely successful, restoring normal immune function in 9 of the 10 children. However, 3 of the patients developed T-cell leukemia due, in part, to the cooperation between the viral insertion, activation of a cellular oncogene, and the growth-promoting characteristics of the therapeutic gene. Interestingly, a similar trial conducted in England, led by Dr. Adrian Thrasher (3), was also successful in treating 4 of $6 \mathrm{X}$ SCID patients with this strategy, and no adverse events have been observed. This suggests that an unknown factor may have been present in the French trial that exacerbated the onset of leukemia.

In the present article, we will summarize the key components of the French trial, analyze the factors that contributed to the unwanted leukemic transformation and explore some of the options for reducing this risk. As stated by the key administrators of these XSCID clinical trials, "research must go on, particularly on vector design" (4). Among the molecular tools currently available, we propose that specialized control of viral expression could help reduce the risk of unwanted oncogene activity. Our work has involved retrovirus-mediated gene transfer for more than 12 years and we are currently developing retroviral vectors with novel transcriptional regulation. We describe here how exploration of vector design as well as transduction and transplantation procedures may improve retrovirus-mediated gene therapy.

\section{Molecular basis of X-linked SCID}

X-SCID is caused by a mutation in the $\gamma$ subunit of the common cytokine receptor $(\gamma c$ or $I L 2 R G$ ), preventing T-cells and natural killer cells from developing. Without functional Tcells, activation of B-cells is also limited, leaving the patient with a severely impaired immune system. The role of the wild-type $\gamma c$ chain (encoded on chromosome Xq13) is to participate in the cytokine receptor complex

Table 1. Principal features of viral vectors.

\begin{tabular}{|c|c|c|c|c|}
\hline Vector & Retrovirus & Lentivirus & Adenovirus & Adenoassociated virus \\
\hline Titer (virus particles $/ \mathrm{mL})^{\mathrm{a}}$ & $10^{9}$ & $10^{9}$ & $10^{12}$ & $10^{12}$ \\
\hline Route of delivery & Ex vivo & Ex vivo & In situ & In situ \\
\hline Integration in the host genome & Yes & Yes & No & Yes/No \\
\hline Long-term expression & Yes & Yes & No & Yes \\
\hline Immune response to viral proteins & No & No & Yes & Yes, but less severe \\
\hline Clinical trials ${ }^{\mathrm{b}}$ & 293 & 8 & 322 & 46 \\
\hline Typical clinical application & $\begin{array}{c}\text { Hematopoietic } \\
\text { system }\end{array}$ & $\begin{array}{c}\text { Hematopoietic } \\
\text { system }\end{array}$ & $\begin{array}{l}\text { Cancer, vaccines, } \\
\text { vascular diseases }\end{array}$ & $\begin{array}{l}\text { Hemophilia, cystic fibrosis, } \\
\text { neurodegenerative disorders }\end{array}$ \\
\hline References & 18,47 & 47,55 & 47 & 47 \\
\hline
\end{tabular}

Titer after concentration of virus preparation; btrials listed on http://www.wiley.co.uk/genmed/clinical/. 
that mediates cellular activation by IL-2, IL-4, IL-7, IL-9, IL-15, and IL-21 $(5,6)$. Since cytokine activation is often associated with proliferation, the cytokine receptor complex, including the $\gamma c$ chain, may represent a growthpromoting assembly.

Without treatment, infants born with XSCID would die within less than a year due to infection $(7,8)$. Treatment requires a bone marrow transplant from a suitable donor, yet not all patients are able to find a match. Perfect matches may be found from siblings, with a $90 \%$ successful transplant rate, or up to about $70 \%$ when the donor is a haploidentical parent or unrelated individual $(9,10)$.

Following transplant, these children are at risk for lymphoma if the donor had a history of infectious mononucleosis. In addition, some transplant recipients do not recover complete T-cell function and most patients have deficient B-cell function, requiring life-long immune-globulin-replacement therapy (9). Efforts to improve B-cell function include chemoablation prior to transplant so that hematopoiesis is restored entirely from transplanted cells, although this approach involves higher mortality (10). Clearly, X-SCID is a devastating disease and standard treatment modalities are inadequate.

\section{Successful gene therapy for X-SCID is associated with three serious adverse events}

A group of French researchers has conducted the most successful gene therapy trial to date, with considerable clinical benefit (though only time will tell if a true cure has been achieved) to 9 of 10 children with $\mathrm{X}$ SCID (11-13). A second clinical trial for this gene therapy approach has been carried out in England and has also been successful in the treatment of 4 of 6 X-SICD patients (3). Until recently, these trials have served as the prime example of how to use molecular tools to treat and essentially cure a disease by the simple insertion of a functional gene into cells that, due to an inherited mutation, would otherwise be lacking that gene's function. The strategy used by Drs. Alain Fischer, Marina CavazzanaCalvo, Adrian Thrasher, and colleagues was ex vivo transduction of CD34+ stem cells, derived from the patient's own bone marrow, with a replication-defective Moloney murine leukemia virus (MLV) vector encoding a normal copy of the $\gamma c$ gene. The transduced cells were then infused into the patients without preparative conditioning. Note that no perfectly matching donor was available for any of the patients in this trial. The age at treatment ranged from 1-11 months $(11,14)$. Of the 16 children treated in these two trials, 15 are still alive and 13 recovered normal $\mathrm{T}$ - and B-cell function, requiring no further treatment, such as immunoglobulin replacement. One infant from the French trial who did not recover immune cell function underwent allogeneic bone marrow transplant (14).

The successfully treated children are able to live in a normal environment and to receive vaccines for common childhood diseases resulting in reactive $\mathrm{T}$ - and $\mathrm{B}$-cells. Some of the patients were treated more than 6 years ago and are considered to be essentially cured, though long-term follow-up will be necessary to firmly establish this conclusion (11-13). In any case, these positive results are the most striking among those obtained in all gene therapy trials.

Tragically, 3 of the children that benefited from the French gene therapy trial have developed a lymphoproliferative disease resembling leukemia due, in part, to the integration of the retroviral gene transfer vehicle near an oncogene $(13,15-17)$. Their white cells were shown to contain a clonal population of $\gamma \delta \mathrm{T}$-cells and this leukemialike condition was treated with chemotherapy and 1 of these patients later died. For 2 of the patients, molecular analyses of these cells showed that the gene transfer vector was present as a single copy, properly expressing the therapeutic gene and that the virally encoded cDNA had not suffered any mutation 
$(13,15)$. However, the site of viral integration was shown to be near a known oncogene, LMO2 (15), as will be addressed in more detail below. The third child was shown to carry 4 viral insertions in the leukemic cells, including at the LMO2 locus $(16,17)$. Much study and debate followed the announcement of these adverse events and a clearer picture is beginning to emerge that depicts their cause, including retroviral integration, oncogene activation and growthpromoting properties of the transgene.

\section{The vector and risk of insertional mutagenesis}

Retroviral vectors based on the Moloney MLV have long been used as the workhorse of gene transfer studies. These vectors are easily manipulated in the laboratory and have several inherent safety features. To date, retroviral vectors have been applied in 293 (representing 23\% of all) clinical trials, making this one of the most popular gene transfer vehicles historically used in the clinical setting which has been applied for the treatment of a variety of diseases, including cancer and hematopoietic deficiencies (http:// www.wiley.co.uk/genmed/clinical/). Except for the French X-SCID trial, no serious adverse events were reported to be associated with the retroviral vector.

Since the virus integrates in the host genome, daughter cells will inherit a copy of the virus. This strategy is beneficial when long-term expression is desired, as in the case of X-SCID (18). Without integration, the viral sequence would eventually be lost after cell division since the virus cannot replicate as an episome. Until recently, the only integrating virus approved for clinical trials was the retrovirus, though eight clinical trials utilizing lentivirus have now been listed for the treatment of HIV (http:// www.wiley. co.uk/genmed/clinical/and Ref. 19). Therefore, the retrovirus is the most popular vector currently available for treat- ments that require prolonged virus expression, such as the correction of immune deficiencies.

The insertion of a recombinant retroviral vector has long been theorized to cause alteration in host-gene expression that could lead to cellular changes, a process known as insertional mutagenesis, but was thought to be too rare an event to be of clinical significance. Mutagenesis, for example, may occur if the virus disrupts an essential gene, thus killing the cell. This is not a threat to the organism or to the gene therapy strategy since this would be a very rare event in a large population of independently transduced cells. Thus, the vast majority of cells would survive the insertion of the viral genome. Moreover, insertion occurs in only one chromosome, leaving the second allele intact, rendering the problem of disabling an essential gene or tumor suppressor less critical (20). In another example, the virus may insert itself near a proto-oncogene and activate its expression. In this case, the presence of the virus would give a proliferative advantage to the cell, a critical first step towards transformation.

In fact, retroviral insertion has been used in order to induce experimental tumors and identify oncogenes involved in the process of transformation, leading to the creation of the Retroviral Tagged Cancer Gene Database (http://RTCGD.ncifcrf.gov). The fact that retroviruses can and do promote tumorigenesis is not new, but was thought to be unrelated to the clinical situation. Experimentally induced tumors are generally created using replication-competent viruses $(21,22)$, whereas the clinical application utilizes viruses that are not able to replicate. Until recently, tumors induced by non-replicating retroviruses had not been observed in pre-clinical gene therapy animal models.

Regulatory elements encoded by the virus may influence local gene expression (Figure 1). In the transduced cell, retroviral expression is driven by either the viral pro- 
moter, called the long-terminal repeat (LTR) or an internal promoter (such as CMV, SV40, ubiquitin, etc.) or by both, permitting a single virus to carry two independent expression cassettes. These promoters encode binding sites for the transcriptional machinery and may act as enhancers which, by definition, may exert an influence over a large distance. In addition, the 3' LTR is a functional promoter that could drive expression of downstream coding regions (20).

When driven by the LTR, retroviral expression is quite strong and promiscuous, especially in cultured cells. However, retroviral expression is often lost in transduced hematopoietic stem cells upon transplantation since differentiation of these cells may lead to chromatin remodeling and methylation of the viral promoter, mechanisms that silence the LTR (23). Expression may be sustained under two conditions: 1) modifications are made in the LTR in order to protect it from methylation (24), and 2) positive selection of transduced cells occurs. In the latter case, the presence of the virus and transgene is beneficial to cell survival, selecting cells that harbor an expressed provirus. The Moloney MLV LTR can drive transgene expression to achieve clinical benefit, though not in all circumstances.

The theoretical risk of activating an oncogene upon recombinant virus insertion in vivo was experimentally proven only recently. Li et al. (25) transduced mouse bone marrow cells with a retroviral vector expressing the $d L N G F R$ marker gene (26) and then transplanted these cells in isogenic recipients. These animals showed no sign of hematologic disturbances when the bone marrow of these primary recipients was pooled and used to transplant secondary recipients. All 10 of the secondary recipients, but only the secondary recipients, developed hematologic disorders, including acute myeloid leukemia in 6 mice (probably due to a clonal population in the pooled cells used for the second transplantation). The virus was shown to insert near the Evil oncogene, activating its expression, and presumably contributing to proliferation. Interestingly, other marker genes did not lead to leukemic transformation in control animals and the authors commented that the transgene, meant to serve as a marker, may have protected the cells against apoptosis, suggesting that the over-abundance of the oncogene combined

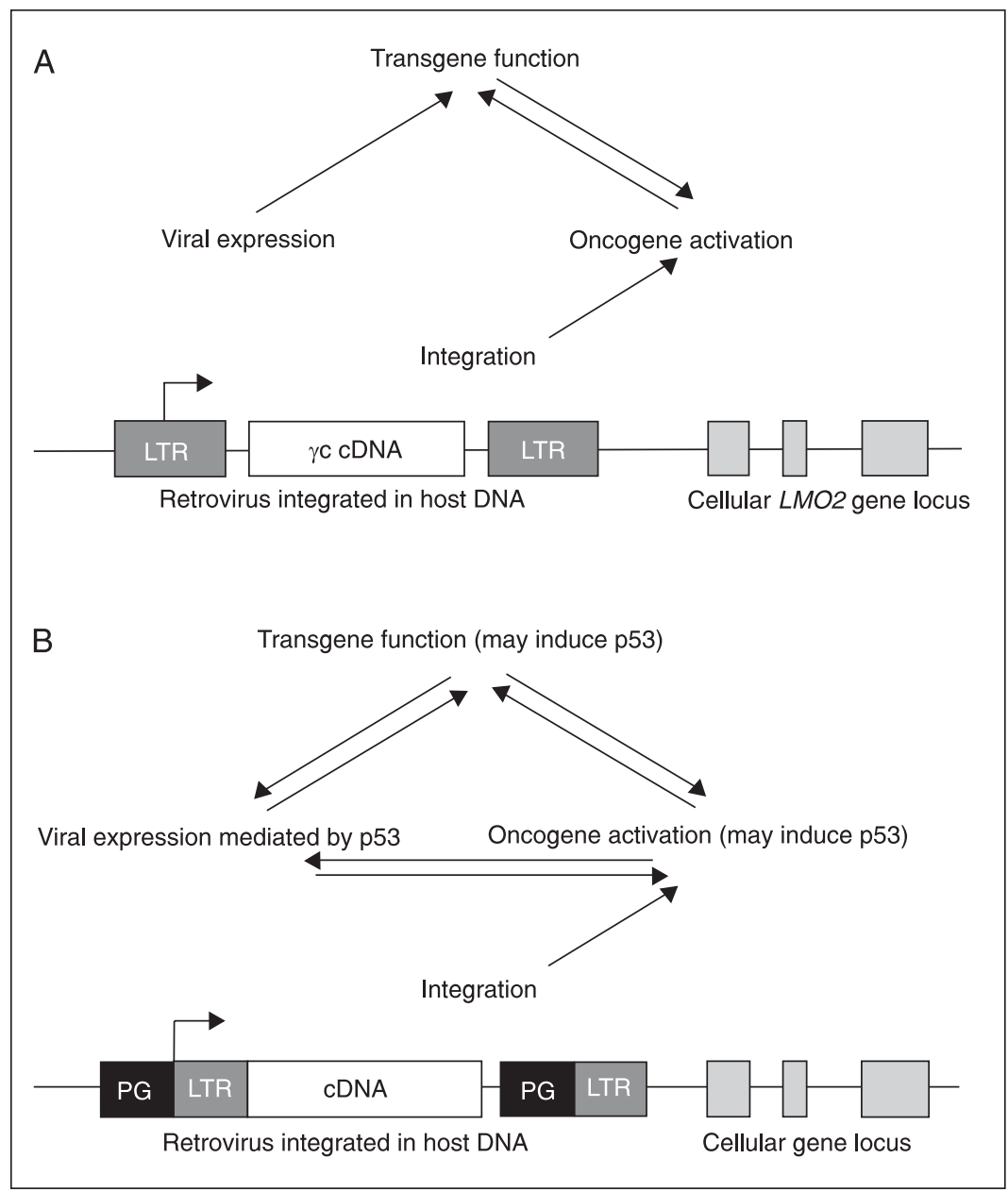

Figure 1. Overview of the influence of the virus on cellular and therapeutic gene expression. Integration of retrovirus in the host genome has been shown to favor regions proximal to the promoter of cellular genes. Viral expression is controlled by the long-terminal repeat (LTR) (viral promoter) which may also influence expression of neighboring cellular genes. $A$, In the cases of leukemia noted in the French X-SCID gene therapy trial, viral integration occurred near the LMO2 oncogene. In addition, $\gamma c$ gene activity may have cooperated with $\angle M O 2$, contributing to proliferation and transformation. B, PCLPG retrovirus expression of the therapeutic gene is controlled by $p 53$ (as shown in Figure 2). We propose that interactions of the transgene, cellular oncogene and p53 may result in p53-mediated cell death, eliminating cells with transformation potential. In addition, replacement of the murine leukemia virus enhancer/promoter with the p53-responsive PG element may reduce spurious transgene expression during T-cell development. 
with the resistance to programmed cell death brought these cells two steps closer to transformation. This study was the first to conclusively prove that insertional mutagenesis by a non-replicating, recombinant retroviral vector could contribute to neoplastic transformation in an animal model (25). Moreover, this study followed the model that viral insertion, oncogene action and transgene function may cooperate and lead to transformation.

Retroviruses were thought to integrate randomly within the host genome. However, this has been proven to be an overly simplistic view. Genomic-style strategies to identify insertion sites and their proximity to candidate genes and regulatory elements $(27,28)$ have shown that MLV retroviruses, such as that used in the X-SCID trial, tend to insert near the promoter region of genes (28). Wu et al. (28) have shown that integration occurs at the locus of a confirmed gene (listed in the RefSeq database) in 34\% of MLV insertion events, whereas HIV or recombinant lentivirus insertions land in RefSeq genes at a frequency of 62 or 50\%, respectively. Even more striking was the observation that MLV vectors show a preference for insertion near $( \pm 1 \mathrm{~kb}) \mathrm{CpG}$ islands associated with transcriptional start sites, yet HIV integrates along the length of the gene locus downstream of the promoter. This may imply that the influence of viral elements on host-gene expression may be stronger for MLV than HIV or lentiviral vectors (28).

These recent observations have helped define the risk associated with retroviral insertion. Especially for MLV, the integration of the virus near gene promoters may represent an increased risk of subsequent mutagenesis.

\section{Cooperation between retroviral insertion, oncogene activity and therapeutic gene function}

A recent study suggests that at least three distinct paths merged and directed the leukemogenic transformation observed in these patients of the French X-SCID gene therapy trial. As described above, insertion near the promoter of a cellular oncogene may bring about activation of its expression. By analyzing a database of insertion sites from cases of mouse hematopoietic tumors caused by wild-type leukemia viruses, Davé et al. (29) have found examples of viral insertion at either the $L M O 2$ gene or the $\gamma c$ chain gene, or both. First, this suggests, as expected, that oncogene activation will contribute to transformation. Second, and unexpectedly, activation of $\gamma c$ could also promote leukemogenesis. Finally, a specific cooperation may exist between $L M O 2$ and $\gamma_{c}$ chain functions, in this instance upon increased expression after viral insertion, that contributes to proliferation and transformation. This study points out that viral integration alone was not responsible for leukemic events, but required other cooperating factors.

Understanding LMO2 may shed some light on its role in the adverse events associated with gene therapy of X-SCID. The LMO2 oncogene encodes a nuclear LIM-only protein that acts as a transcription factor necessary for erythroid development $(16,30)$. $L M O 2^{-/-}$mice die at embryonic day 10.5 due, in part, to a lack of hematopoiesis (31); yet transgenic mice overexpressing $L M O 2$ in the thymus developed T-cell leukemia $(32,33)$. Normal LMO2 expression occurs in a variety of tissue types, such as kidney, liver, lung, spleen, and the central nervous system (34), in addition to myeloid and erythroid cells (31). LMO2 has also been implicated in promoting angiogenesis and capillary remodeling, processes clearly impeded in $\mathrm{LMO}^{-/-}$mice (35). Therefore, LMO2 is necessary, but uncontrolled expression can contribute to leukemia. In the $\mathrm{X}$ SCID patients who developed leukemia, $L M O 2$ activity is thought to have played a major part in promoting cellular transformation.

Was the $\mathrm{LMO} 2$ site targeted by the virus? Based on the current understanding of retrovirus integration, the number of human genes and the number of transduced cells 
that each patient received, it has been estimated that each patient would have been injected with 10-100 cells harboring insertion at a given expressed gene locus, including the LMO2 site (30). Since this integration site was identified in relatively few patients, it may not represent a favored site, but rather an available one. Subsequently, cooperation between $L M O 2$ and $\gamma c$ may have provided an advantage for proliferation, selectively expanding this population of cells (Figures 1 and 2). Therefore, the insertion event, activation of $L M O 2$ and its potential cooperation with $\gamma c$ chain functions all con-

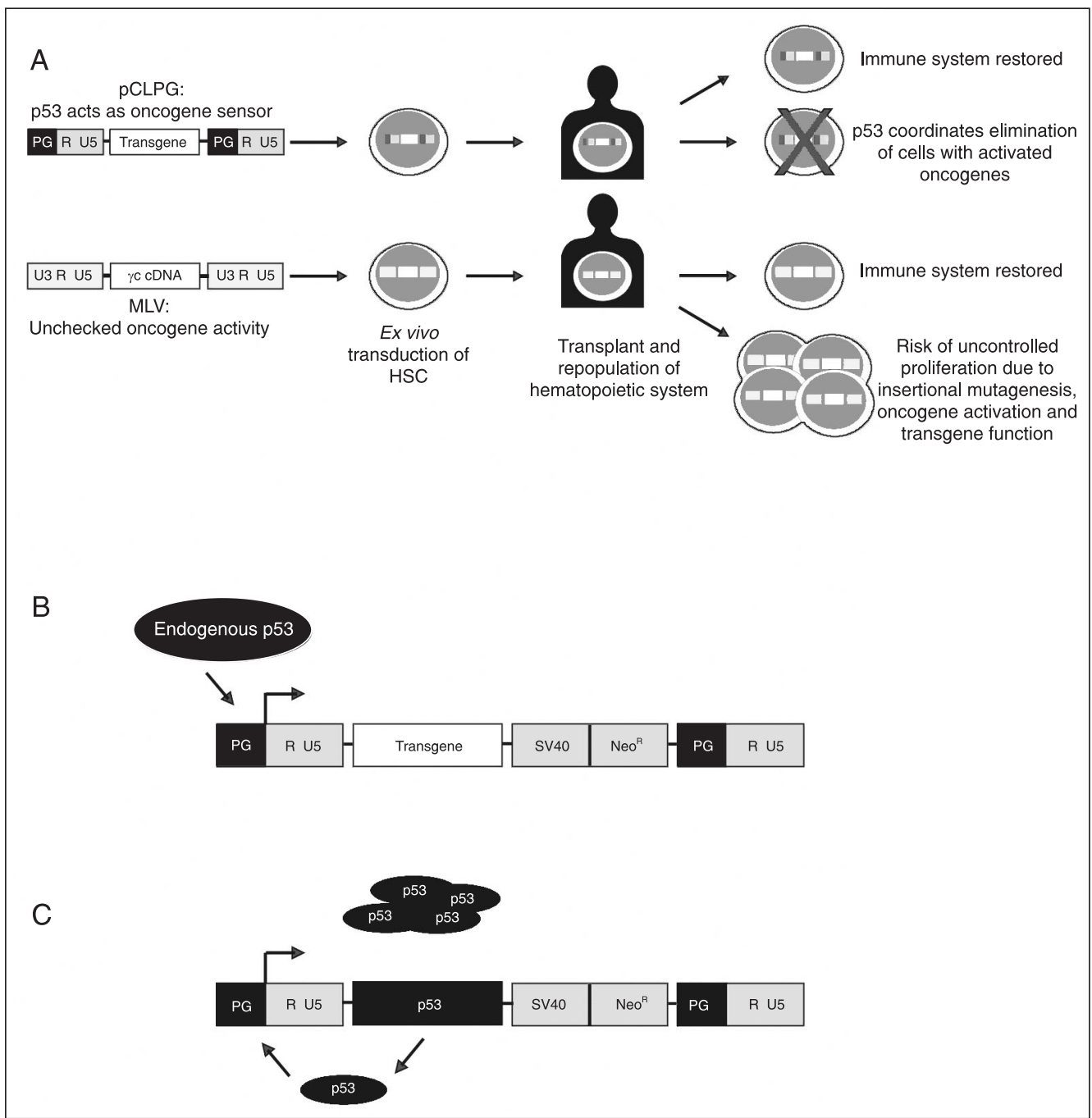

Figure 2. Representation of the events related to oncogene activation during retrovirus-mediated gene therapy. $A$, We propose that the use of p53 as a transcription factor for our modified retroviral vector, pCLPG, may also serve as an oncogenic sensor since feedback between oncogene, transgene and p53 activities may result in cell death coordinated by p53. Standard murine leukemia virus (MLV) retroviral vectors have been shown to cause uncontrolled proliferation in gene therapy applications. $B$, The retroviral long-terminal repeat was modified by the removal of the promoter/enhancer region and insertion of the p53-responsive PG element, as described previously $(56,57)$. Endogenous p53 can drive expression of the therapeutic transgene when encoded by the pCLPG retrovirus. We propose that this arrangement may be beneficial for gene therapy of hematopoietic diseases. $C$, Another use for the PCLPG strategy is the creation of an auto-regulatory cycle, where p53 is encoded by the virus and acts as the activator of viral expression. When p53 transcription is driven by the p53-responsive promoter, a positive feedback loop is established, resulting in high-level expression and superior anti-tumor activity (57). A transgene combination of $\gamma c$ plus p53 may prove beneficial. HSC $=$ hematopoietic stem cell. 
tributed to the leukemogenesis. This understanding may then serve as a starting point for improving future gene therapy applications (36).

A clear and proportional relationship between the transduction efficiency, number of proviral integration sites, and tendency to clonal expansion (including leukemogenesis) has been observed when oncoretroviral particles are introduced into hematopoietic progenitor cells. Transduction, the process of introducing a recombinant virus into a target cell, can be characterized by the number of virus particles applied to the cells. This relationship, called multiplicity of infection (MOI), reveals the number of virus particles/ target cell present during transduction. For example, 4000 virus particles applied to 2000 cells would have an MOI of 2 . In this example we may be tempted to expect that all of the cells would be transduced, but the actual transduction efficiency is much lower, since some particles may never enter a cell and some cells may receive more than one particle.

At low virus concentrations ( $\mathrm{MOI} \leq 1$ ), transduction of a target cell with a retroviral vector typically results in a single particle entering the cell. However, at higher MOI several virus particles may enter a single target cell, as was recently shown by quantitative methods (37). Therefore, seeking higher transduction efficiencies by increasing the MOI may lead to increased risk of insertional mutagenesis, though single insertion sites were observed in two of the three leukemias that resulted from the French X-SCID trial (13).

A recent paper has shown that at low virus concentration, transduction of hematopoietic stem cells (HSC) can avoid the leukemogenesis that was observed at higher virus concentrations (38). An oncoretroviral vector encoding the human multidrug resistance gene-1 (MDRI), a membrane-bound drug efflux pump, was used to transduce HSC at low or high doses and these cells were then transplanted in myeloablated, isogenic recipient mice. These investigators found that at the low dose no leukemias developed even though virus insertion did occur at or near oncogene loci. In contrast, $50 \%$ of the animals transplanted with HSC transduced with high doses of the virus developed leukemia. The activity of the MDRI gene, which may protect against apoptosis, may also have been a contributing factor since animals receiving HSC transduced with a virus encoding a fluorescent protein did not develop leukemia due to viral insertion. This recent work shows, for the first time, the relationship between oncoretroviral transduction efficiency and malignant risk in an animal model.

Clonal expansion, the accelerated proliferation of a small number of progenitor cells, yields reduced variation in the resulting hematopoietic populations and is a hallmark of nonmalignant and malignant hematopoiesis. Retroviruses have long been used as markers of clonal expansion since their insertion sites can be used to identify cell populations. However, it has been shown that the viral insertion itself may contribute to nonmalignant clonal expansion. Kustikova et al. (39) have shown that, upon transduction of HSC followed by serial transplantation in irradiated recipient mice, clonal expansion was associated with viral insertion at oncogene loci. They postulated that these cells had enhanced "fitness" due to unregulated oncogene expression, though they did not turn malignant. Interestingly, this situation has been mirrored in the clinical setting. A recent gene therapy trial for X-linked chronic granulomatous disease showed that retroviral delivery of the $g p 91^{\text {phox }}$ gene yielded an improvement in immune function, though viral activation of cellular oncogenes may have contributed to this success (40).

New developments suggest that the growth-promoting action of $\gamma c$ may be as important as viral insertion, or even more, in promoting oncogenesis. Woods et al. (41) 
showed that a lentiviral vector with inactivated LTRs and containing the CAG promoter to drive $\gamma c$ induced lymphoma in a mouse model of X-SCID gene therapy, but did not when green fluorescent protein was expressed. This suggests that the viral insertion itself was not responsible for the transformation, but $\gamma c$ activity was. Similarly, these investigators showed that viral expression of $L M O 2$ could also induce transformation in this model of X-SCID treatment. They observed the animals over an extended period of time and noted the onset of lymphomas at 6 months post-transplantation, a key difference compared to other preclinical studies of X-SCID gene therapy which did not provide follow-up beyond 6 months. Details of the lentiviral insertion sites have not been revealed, but these investigators note that several insertion sites were present in transduced cells and that this profile was different for each animal. This study did not directly address vector design, therefore it is difficult to infer if lentiviral vectors may provide an advantage over the use of MLV. This study suggests that $\gamma c$ function can contribute to transformation.

The target cell phenotype may also have been a contributing factor in the development of leukemia. In a new study, an increased tendency towards transformation was observed in a mouse model of X-SCID gene therapy where the $\gamma c$ gene was introduced in bone marrow cells with a retroviral vector, but transformation was less likely when the treatment was performed with cells derived from a non-X-SCID animal. This suggests that the X-SCID phenotype may have played a role in permitting transformation to occur in the presence of the retrovirus and $\gamma c$ gene (42).

Viral integration alone was not sufficient to promote transformation in the patients of the French X-SCID trial, but insertion into the $L M O 2$ locus was likely to be a factor contributing to the inappropriate expression of this oncogene. The activities of both $L M O 2$ and the therapeutic gene, $\gamma c$, influenced the formation of leukemia. The specific role of viral insertion, oncogene activation and transgene activity continues to be studied, as described below, with the hope of developing strategies that preserve therapeutic benefit without elevating the risk of adverse events.

\section{The response from regulatory agencies and the gene therapy community}

When the first case of leukemia resulting from the French gene therapy trial was announced, US, French and British agencies halted trials temporarily, but then allowed them to continue, believing that the case was isolated (43). However, the announcement of the second case and the identification of the frequency of viral insertion at the $\mathrm{LMO} 2$ locus in these children prompted US agencies to stop 27 trials using retroviral gene transfer to hematopoietic stem cells (44). Continuation of these trials has been permitted on a case-by-case basis. The French trial was reinitiated (45), but was again put on hold when the third case of leukemia was discovered. Analysis of the risk $v s$ benefit for the treatment of X-SCID by gene therapy has led many to believe that the cure of the underlying disease by far outweighs the risk of a serious side effect. Trials using a retrovirus for the treatment of SCID due to ADAdeficiency have been allowed to continue in the US.

The gene therapy community has responded to the unfortunate developments in the French trial by carefully analyzing experimental data that were available both before and after these occurrences $(4,18,46-$ 48). As shown in Table 2, the French and British X-SCID gene therapy trials were quite similar in their design and execution, yet the adverse events have been seen only in the French trial. In order to foresee such events, more extensive pre-clinical animal studies have been recommended, as described in 
Table 3. One point that is repeatedly raised is the need for improved vector design, including improved transcriptional control (49).

\section{Strategies for combating oncogene activation in transduced cells}

New technologies that do not rely on random viral integration may one day be developed for the treatment of X-SCID. For example, site-specific integration may permit introduction of the wild-type $\gamma c$ gene at genomic locations known to be void of genes or regulatory elements $(50,51)$. Alternatively, the endogenous $\gamma c$ gene may be corrected $e x$ vivo by means of homologous recombination promoted by engineered zinc-finger proteins, avoiding the need for viral integration (52). Both of these technologies, though promising, are far from being ready for clinical application.

Other viral vectors may also be explored to deliver the $\gamma c$ gene. Adenovirus would not be an appropriate choice since this vector does not provide long-term stability or sustained transgene expression. Adeno-associ-

Table 2. Potential factors contributing to the development of leukemia in the French X-linked severe combined immunodeficiency (X-SCID) trial and differences, when present, compared to the British trial.

\begin{tabular}{|c|c|c|c|}
\hline Factor & Issue & French trial ${ }^{\mathrm{a}}$ & British triala \\
\hline$\gamma c$ gene & Promotes proliferation & & \\
\hline Stem cell phenotype in X-SCID patients & $\begin{array}{l}\text { Good proliferation, accumulation } \\
\text { of undifferentiated cells }\end{array}$ & & \\
\hline $\begin{array}{l}\text { Proportionately high number of CD34+ } \\
\text { cells injected }\end{array}$ & $\begin{array}{l}\text { Inceased risk of cells suffering } \\
\text { insertional mutagenesis }\end{array}$ & & \\
\hline High level of $\gamma c$ expression & Could cause unwanted proliferation & & \\
\hline Immune deficiency of the subjects & $\begin{array}{l}\text { Permits rapid expansion of cells to } \\
\text { fill empty niches }\end{array}$ & & \\
\hline Cooperation between $\gamma c$ and $L M O 2$ & $\begin{array}{l}\text { Growth-promoting activity that } \\
\text { contributes to transformation }\end{array}$ & & \\
\hline Vector design & $\begin{array}{l}\text { Retrovirus derived from Moloney } \\
\text { MLV, LTR used to drive transgene } \\
\text { expression, virtually identical in } \\
\text { both trials }\end{array}$ & $\begin{array}{l}\text { B2 mutation in the } \\
\text { primer binding site } \\
\text { included to help } \\
\text { reduce vector silencing }\end{array}$ & $\begin{array}{l}\text { Native primer binding } \\
\text { site }\end{array}$ \\
\hline $\begin{array}{l}\text { Age at time of treatment of subjects } \\
\text { who developed leukemia }\end{array}$ & $\begin{array}{l}\text { May introduce virus and transgene } \\
\text { at a critical moment in the } \\
\text { development of the immune sytem }\end{array}$ & $\begin{array}{l}2 \text { patients treated before } \\
3 \text { months of age, } 1 \text { patient } \\
\text { treated at } 9 \text { months of age }\end{array}$ & $\begin{array}{l}\text { No cases of leukemia } \\
\text { reported }\end{array}$ \\
\hline $\begin{array}{l}\text { High level of transduction/ } \\
\text { transduction protocol }\end{array}$ & $\begin{array}{l}\text { Entry of multiple virus particles could } \\
\text { increase risk of insertional } \\
\text { mutagenesis }\end{array}$ & $\begin{array}{l}\text { Transduction protocol } \\
\text { designed to enhance } \\
\text { efficiency by use of protamine } \\
\text { sulfate, IL-3 }(60 \mathrm{ng} / \mathrm{mL})\end{array}$ & $\begin{array}{l}\mathrm{IL}-3(30 \mathrm{ng} / \mathrm{mL}) \text { and } \\
\text { no protamine sulfate }\end{array}$ \\
\hline Pseudotype & $\begin{array}{l}\text { Viral envelope protein that } \\
\text { determines tropism }\end{array}$ & Amphotrophic MLV & $\begin{array}{l}\text { Gibbon Ape leukemia } \\
\text { virus }\end{array}$ \\
\hline Rate of T-cell expansion & May influence leukemogenesis & $\begin{array}{l}\text { Leukemic: plateau reached } \\
\text { in 3-4 months } \\
\text { Non-leukemic: plateau reached } \\
\text { in } 4-6 \text { months }\end{array}$ & $\begin{array}{l}\text { Plateau reached in } 10 \\
\text { months }\end{array}$ \\
\hline
\end{tabular}

MLV = murine leukemia virus; LTR = long-terminal repeat.

aAdapted from Nienhuis et al. (47). 
ated virus is being considered for hematopoietic targets, though viral insertion events have been noted in hemophilia patients in a gene therapy trial (53). Lentiviruses, the family to which HIV belongs, have been developed as recombinant gene transfer vectors and have also been shown, under certain conditions, to initiate oncogenesis due to insertional mutagenesis (54) or transgene activity (41). However, a recent study has suggested that lentiviral vectors may be safer than MLV when applied to hematopoietic stem cells (55). Retroviral vectors developed from non-MLV sources are also being evaluated with respect to their reduced propensity to integrate near promoter regions $(48,56)$.

Assuming that no alternative to the use of the $\gamma c$ gene or integrating vectors is available for X-SCID gene therapy, we are left with few options other than to find a balance between the efficiency that viral vectors provide and the growth-promoting properties of $\gamma c$. Improved safety for retroviral vector design has been proposed and is within the reach of current technology $(18,48)$. These strategies include inactivation of the LTR, use of an internal promoter to drive transgene expression, and the inclusion of a suicide gene to permit the selective elimination of transduced cells. However, the work of Woods et al. (41) suggests that LTR inactivation and the use of an internal promoter were not satisfactory.
Another strategy in development includes an anti-oncogenic sensor that would eliminate cells destined for transformation. Our current research is related to the development of retroviral vectors with modified transcriptional control. Expression from one of these vectors, called pCLPG (Figure 2), is controlled by the tumor suppressor and transcription factor, p53 $(57,58)$. We have initiated experimental work, which will take several years to complete, to determine if the employment of cellular p53 to drive viral expression might also be useful for combating oncogene activation. Our expectation is that a feedback mechanism would be established between the oncogene and p53, resulting in the elimination of that cell by apoptosis coordinated by p53 (Figures 1 and 2). This feedback mechanism may include the activity of the transgene, such as $\gamma c$ or $d L N G F R$, whose growth-promoting or antiapoptotic activity may induce the protective functions of p53. The novel transcriptional control strategy present in the pCLPG system may prove to be interesting in other gene therapy models where proliferation stimulated by the transgene is problematic.

We suspect that modifications of the LTR will have an added benefit beyond the use of the p53 tumor suppressor to drive expression and sense oncogene activity. The native Moloney MLV LTR is especially active in developing thymocytes which may promote transgene and oncogene expression at a par-

\footnotetext{
Table 3. Recommendations by the American Society of Gene Therapy for hematopoietic stem cell gene transfer studies in animal models.

Follow-up of at least 12 months

Hematological analyses and autopsies performed in long-term transplant recipients

Analysis of viral integration sites related to cell type, transduction conditions, clonal expansion, duration of transgene expression, and toxicity in long-term transplant recipients

Establish database of integration sites

Test therapeutic genes in a relevant disease model

Animal studies should approximate human trial conditions

Novel transgenes should be tested in transgenic mice as well as in transplant recipients
} 
ticularly sensitive moment in T-cell maturation. In the pCLPG system, the Moloney MLV enhancer/promoter elements have been eliminated and thus unwanted LTR activity may be avoided during T-cell lymphopoiesis. These ideas remain to be tested experimentally, a process that depends on extensive animal and molecular studies.

\section{Impact on future studies}

The next generation of vectors and gene therapy trials will involve higher standards. Gene therapy has been proven effective by the X-SCID trials, yet a potential risk has also been demonstrated. Unquestionably, 10 children were successfully treated by the French and British gene therapy trials and did not show any adverse effects, a point that must be underscored when considering the risk of retrovirus-mediated treatment. Clearly, the combination of viral integration, oncogene activation and transgene activity were contributing factors to the leukemic events. However, a critical difference has not yet come to light between the French and British trials that could indicate how to avoid leukemogenesis and yet maintain the clinical benefit seen in both protocols. Future trials will benefit from continued study of vectors, target cells, transduction strategies, and relevant animal models.

\section{References}

1. Gaspar HB, Thrasher AJ. Gene therapy for severe combined immunodeficiencies. Expert Opin Biol Ther 2005; 5: 1175-1182.

2. Srivastava A. Hematopoietic stem cell transduction by recombinant adeno-associated virus vectors: problems and solutions. Hum Gene Ther 2005; 16: 792-798.

3. Gaspar HB, Parsley KL, Howe S, King D, Gilmour KC, Sinclair J, et al. Gene therapy of X-linked severe combined immunodeficiency by use of a pseudotyped gammaretroviral vector. Lancet 2004; 364: 2181-2187.

4. Cavazzana-Calvo M, Thrasher A, Mavilio F. The future of gene therapy. Nature 2004; 427: 779-781.

5. Schmalstieg FC, Goldman AS. Immune consequences of mutations in the human common gamma-chain gene. Mol Genet Metab 2002; 76: 163-171.

6. Malek TR, Porter BO, He YW. Multiple gamma c-dependent cytokines regulate T-cell development. Immunol Today 1999; 20: 71-76.

7. Rosen FS, Cooper MD, Wedgwood RJ. The primary immunodeficiencies. N Engl J Med 1995; 333: 431-440.

8. Buckley RH. Primary immunodeficiency diseases due to defects in lymphocytes. N Engl J Med 2000; 343: 1313-1324.

9. Buckley RH, Schiff SE, Schiff RI, Markert L, Williams LW, Roberts $\mathrm{JL}$, et al. Hematopoietic stem-cell transplantation for the treatment of severe combined immunodeficiency. N Engl J Med 1999; 340: 508516.

10. Haddad E, Landais P, Friedrich W, Gerritsen B, Cavazzana-Calvo $M$, Morgan $G$, et al. Long-term immune reconstitution and outcome after HLA-nonidentical T-cell-depleted bone marrow transplantation for severe combined immunodeficiency: a European retrospective study of 116 patients. Blood 1998; 91: 3646-3653.

11. Hacein-Bey-Abina S, le Deist F, Carlier F, Bouneaud C, Hue C, de Villartay JP, et al. Sustained correction of $X$-linked severe combined immunodeficiency by ex vivo gene therapy. N Engl J Med 2002; 346: 1185-1193.

12. Cavazzana-Calvo M, Hacein-Bey S, de Saint Basile G, Gross F,
Yvon E, Nusbaum P, et al. Gene therapy of human severe combined immunodeficiency (SCID)-X1 disease. Science 2000; 288: 669-672.

13. Hacein-Bey-Abina S, Von Kalle C, Schmidt M, McCormack MP, Wulffraat $\mathrm{N}$, Leboulch $\mathrm{P}$, et al. LMO2-associated clonal T cell proliferation in two patients after gene therapy for SCID-X1. Science 2003; 302: 415-419.

14. Buckley RH. Gene therapy for SCID - a complication after remarkable progress. Lancet 2002; 360: 1185-1186.

15. Hacein-Bey-Abina S, Von Kalle C, Schmidt M, le Deist F, Wulffraat $\mathrm{N}$, Mclntyre $\mathrm{E}$, et al. A serious adverse event after successful gene therapy for $\mathrm{X}$-linked severe combined immunodeficiency. $N$ Engl $J$ Med 2003; 348: 255-256.

16. Nam CH, Rabbitts TH. The role of LMO2 in development and in $\mathrm{T}$ cell leukemia after chromosomal translocation or retroviral insertion. Mol Ther 2006; 13: 15-25.

17. Frederickson RM. Report from the 2nd stem cell clonality and genotoxicity retreat. Mol Ther 2005; 12: 379-383.

18. Baum C, Dullmann J, Li Z, Fehse B, Meyer J, Williams DA, et al. Side effects of retroviral gene transfer into hematopoietic stem cells. Blood 2003; 101: 2099-2114.

19. Aberg JA, Williams PL, Liu T, Lederman HM, Hafner R, Torriani FJ, et al. A study of discontinuing maintenance therapy in human immunodeficiency virus-infected subjects with disseminated Mycobacterium avium complex: AIDS Clinical Trial Group 393 Study Team. J Infect Dis 2003; 187: 1046-1052.

20. Trono D. Virology. Picking the right spot. Science 2003; 300: 16701671.

21. Lund AH, Turner G, Trubetskoy A, Verhoeven E, Wientjens E, Hulsman D, et al. Genome-wide retroviral insertional tagging of genes involved in cancer in Cdkn2a-deficient mice. Nat Genet 2002; 32: $160-165$.

22. Mikkers $\mathrm{H}$, Berns $\mathrm{A}$. Retroviral insertional mutagenesis: tagging cancer pathways. Adv Cancer Res 2003; 88: 53-99.

23. Challita PM, Kohn DB. Lack of expression from a retroviral vector 
after transduction of murine hematopoietic stem cells is associated with methylation in vivo. Proc Natl Acad Sci U S A 1994; 91: 25672571.

24. Challita PM, Skelton D, el-Khoueiry A, Yu XJ, Weinberg K, Kohn DB. Multiple modifications in cis elements of the long terminal repeat of retroviral vectors lead to increased expression and decreased DNA methylation in embryonic carcinoma cells. J Virol 1995; 69: 748-755.

25. Li Z, Dullmann J, Schiedlmeier B, Schmidt M, Von Kalle C, Meyer J, et al. Murine leukemia induced by retroviral gene marking. Science 2002; 296: 497.

26. Bonini C, Ferrari G, Verzeletti S, Servida P, Zappone E, Ruggieri L, et al. HSV-TK gene transfer into donor lymphocytes for control of allogeneic graft-versus leukemia. Science 1997; 276: 1719-1724.

27. Schmidt M, Zickler P, Hoffmann G, Haas S, Wissler M, Muessig A, et al. Polyclonal long-term repopulating stem cell clones in a primate model. Blood 2002; 100: 2737-2743.

28. Wu X, Li Y, Crise B, Burgess SM. Transcription start regions in the human genome are favored targets for MLV integration. Science 2003; 300: 1749-1751.

29. Dave UP, Jenkins NA, Copeland NG. Gene therapy insertional mutagenesis insights. Science 2004; 303: 333.

30. McCormack MP, Rabbitts TH. Activation of the T-cell oncogene LMO2 after gene therapy for $\mathrm{X}$-linked severe combined immunodeficiency. N Engl J Med 2004; 350: 913-922.

31. Warren AJ, Colledge WH, Carlton MB, Evans MJ, Smith AJ, Rabbitts $\mathrm{TH}$. The oncogenic cysteine-rich LIM domain protein rbtn2 is essential for erythroid development. Cell 1994; 78: 45-57.

32. Larson RC, Osada H, Larson TA, Lavenir I, Rabbitts TH. The oncogenic LIM protein Rbtn2 causes thymic developmental aberrations that precede malignancy in transgenic mice. Oncogene 1995; 11: 853-862.

33. Larson RC, Lavenir I, Larson TA, Baer R, Warren AJ, Wadman I, et al. Protein dimerization between Lmo2 (Rbtn2) and Tal1 alters thymocyte development and potentiates $\mathrm{T}$ cell tumorigenesis in transgenic mice. EMBO J 1996; 15: 1021-1027.

34. Foroni L, Boehm T, White L, Forster A, Sherrington P, Liao XB, et al. The rhombotin gene family encode related LIM-domain proteins whose differing expression suggests multiple roles in mouse development. J Mol Biol 1992; 226: 747-761.

35. Yamada Y, Warren AJ, Dobson C, Forster A, Pannell R, Rabbitts $\mathrm{TH}$. The $\mathrm{T}$ cell leukemia LIM protein Lmo2 is necessary for adult mouse hematopoiesis. Proc Natl Acad Sci U S A 1998; 95: 38903895.

36. Berns A. Good news for gene therapy. N Engl J Med 2004; 350: 1679-1680.

37. Kustikova OS, Wahlers A, Kuhlcke K, Stahle B, Zander AR, Baum $\mathrm{C}$, et al. Dose finding with retroviral vectors: correlation of retroviral vector copy numbers in single cells with gene transfer efficiency in a cell population. Blood 2003; 102: 3934-3937.

38. Modlich U, Kustikova OS, Schmidt M, Rudolph C, Meyer J, Li Z, et al. Leukemias following retroviral transfer of multidrug resistance 1 (MDR1) are driven by combinatorial insertional mutagenesis. Blood 2005; 105: 4235-4246.

39. Kustikova O, Fehse B, Modlich U, Yang M, Dullmann J, Kamino K, et al. Clonal dominance of hematopoietic stem cells triggered by retroviral gene marking. Science 2005; 308: 1171-1174.

40. Ott MG, Schmidt M, Schwarzwaelder K, Stein S, Siler U, Koehl U, et al. Correction of $\mathrm{X}$-linked chronic granulomatous disease by gene therapy, augmented by insertional activation of MDS1-EVI1, PRDM16 or SETBP1. Nat Med 2006; 12: 401-409.

41. Woods NB, Bottero V, Schmidt M, Von Kalle C, Verma IM. Gene therapy: therapeutic gene causing lymphoma. Nature 2006; 440: 1123.

42. Shou Y, Ma Z, Lu T, Sorrentino BP. Unique risk factors for insertional mutagenesis in a mouse model of XSCID gene therapy. Proc Natl Acad Sci U S A 2006; 103: 11730-11735.

43. Kaiser J. Gene therapy. RAC's advice: proceed with caution. Science 2002; 298: 2113-2115.

44. Check E. Second cancer case halts gene-therapy trials. Nature 2003; 421: 305.

45. Check E. Gene therapists hopeful as trials resume with childhood disease. Nature 2004; 429: 587.

46. Friedmann T. Gene therapy's new era: a balance of unequivocal benefit and unequivocal harm. Mol Ther 2003; 8: 5-7.

47. Thomas CE, Ehrhardt A, Kay MA. Progress and problems with the use of viral vectors for gene therapy. Nat Rev Genet 2003; 4: 346358.

48. Nienhuis AW, Dunbar CE, Sorrentino BP. Genotoxicity of retroviral integration in hematopoietic cells. Mol Ther 2006; 13: 1031-1049.

49. Schambach A, Bohne J, Chandra S, Will E, Margison GP, Williams DA, et al. Equal potency of gammaretroviral and lentiviral SIN vectors for expression of O6-methylguanine-DNA methyltransferase in hematopoietic cells. Mol Ther 2006; 13: 391-400.

50. Groth AC, Calos MP. Phage integrases: biology and applications. $J$ Mol Biol 2004; 335: 667-678.

51. Ishikawa Y, Tanaka N, Murakami K, Uchiyama T, Kumaki S, Tsuchiya S, et al. Phage phiC31 integrase-mediated genomic integration of the common cytokine receptor gamma chain in human $\mathrm{T}$ cell lines. J Gene Med 2006; 8: 646-653.

52. Urnov FD, Miller JC, Lee YL, Beausejour CM, Rock JM, Augustus S, et al. Highly efficient endogenous human gene correction using designed zinc-finger nucleases. Nature 2005; 435: 646-651.

53. Check E. Harmful potential of viral vectors fuels doubts over gene therapy. Nature 2003; 423: 573-574.

54. Themis M, Waddington SN, Schmidt M, Von Kalle C, Wang Y, AlAllaf $F$, et al. Oncogenesis following delivery of a nonprimate lentiviral gene therapy vector to fetal and neonatal mice. Mol Ther 2005; 12: 763-771.

55. Montini E, Cesana D, Schmidt M, Sanvito F, Ponzoni M, Bartholomae $\mathrm{C}$, et al. Hematopoietic stem cell gene transfer in a tumor-prone mouse model uncovers low genotoxicity of lentiviral vector integration. Nat Biotechnol 2006; 24: 687-696.

56. Baum C, Schambach A, Bohne J, Galla M. Retrovirus vectors: toward the plentivirus? Mol Ther 2006; 13: 1050-1063.

57. Strauss BE, Costanzi-Strauss E. pCLPG: a p53-driven retroviral system. Virology 2004; 321: 165-172.

58. Strauss BE, Bajgelman MC, Costanzi-Strauss E. A novel gene transfer strategy that combines promoter and transgene activities for improved tumor cell inhibition. Cancer Gene Ther 2005; 12: 935 946. 